\title{
The Perks of Politeness Translation Strategies
}

\author{
Alireza Akbari \\ Foreign Language Faculty, University of Isfahan, Isfahan, Iran
}

\begin{abstract}
Translation of polite expressions is an arduous task of the translator. Every culture presents its own system of polite expression in the source language. Therefore, the translator should prepare the mutual situation in source and target language in order to convey the near sense of polite expressions. Politeness Principles (PP) and Positive-Negative Politeness were proposed by Geoffrey Leech (1983) and Brown-Levinson (1987) respectively. The present paper seeks to find some translation strategies in dealing with polite expressions across cultures. And finally, this study is based on the English-Italian instances to test the workability of the defined politeness translation strategies to see the similarities and difference between the intended languages.
\end{abstract}

Index Terms - translation of polite expressions, culture, Politeness Principle, Positive-Negative Politeness, translation strategies

\section{INTRODUCTION}

\section{A. A Brief Description of Politeness in Translation}

Politeness is a speech event which is of great importance in translation as the main transference essence in crosscultural communication. Politeness is the natural phenomenon amongst people but it needs more considerable attention in cross-cultural communication. Generally speaking, when the translator know how to deal with grammatical structure of the Target Language, then he or she should prepare the situation to deal with pragmatic aspects of language such as politeness (either on record, bald on record, or off record), Illocutionary Force Indicating Device (IFID), presuppositions, and implicatures.

With the amelioration of economic trade amongst cultures, the need to perceive the source and target language is of great rigorous. Each culture has its own system of transferring polite words to others. It can be said that politeness intensification is of great importance for renderer to translate and then transfer them to the target reader. But, sometimes cultural overlaps will be pernicious in the target language. For instance, the Russian language does not utilize the "Please" word in formal situation (Oxenden and Latham-Koenig, American English File, 2008, p.38). While in British culture, the word "Please" has the most intensifying appellation amongst people. How can the Russian renderer deal with this situation to transfer the exact content of the source language without any chops and changes? Or, how can a Japanese Translator transfer the social deixis (both relational and absolute) to English translation and make the same understanding in the target language (Archer, Aijmer, Wichmann, 2012, p.27). The other note will be Face Threatening Act which should be done very cautiously in politeness. In some situations, the translator should decrease the sense of face threatening act in the target language or should somehow modify the structure of the politeness when transferring the content. But the very important fact is that he or she should determine the red line in his or her translation. Passing the red line means breaking the laws of translation and changing the content thoroughly. According to Hatim and Mason (1997, p.147), the translator should be a mediator between the source and target languages. They defined mediation "the extents to which translators intervene in the transfer process, feeling their own knowledge and belief into processing the text." But in this direction, some translators depend themselves to notion of "Les Belles Infidèles" which means "translation as being belles (beautiful) and Infidèles (unfaithful) (Chamberlain, 1998/2000, p.315)." In this track, they devote themselves to natural equivalence or one to one correspondence and they want to build up the similar situation in the target language. This strategy was well-adapted in the time of Structuralism who studies the innerrelations in the language system. How can the translator prepare the outer situations in the target language? As it can be understood, pragmatic markers such as politeness, face want are in outer layer of language system. They should be conveyed systematically which bear no offensive track in target language. Therefore, the translator should scrutinize the language resistancy prior to the act of translation (Akbari, 2011). The note to be considered will be the role of "decoding ability" in translation of politeness. Decoding ability in any language involves at least four principal levels: (1) the capacity of children whose vocabulary and cultural experience are limited. (2) The double standard of capacity of new literates, who can decode oral message with facility but whose ability to decode written message is limited. (3) the capacity of average literate adult, who can handle both oral and written messages with relative ease; and (4) the unusually high capacity of specialists (doctors, theologians, philosophers, scientists, etc.), when they are decoding messages within their own area specialization (Eugene Nida, 1964, p.156-171). Transferring the politeness strategies in these four groups can be an arduous task. Saturation of the needs of the target reader requires utilizing some new strategies in translation which can connect the reader or hear to the text and preventing any incoming premonition in rendering. 


\section{B. The Scope of Study}

In order to get an exact understanding, this study seeks in investigate the perks of politeness strategies in translation of English-Italian sentences to see the discrepancies between these two languages ins and outs. This study covers new politeness strategies in translation to meet the needs of the target reader in this direction.

\section{The Significance of Study}

The author anticipates some new strategies when dealing in every situation both theoretically and practically. Theoretically in a way that is completely utilizable amongst various cultures and practically for those who want to inspect the nature of politeness strategies in translation to procure an incredible interpretation or rendering in the target language and depict the deference strategy (Yule, 1947, p.66) of the source language.

\section{REVIEW OF LITERATURE}

\section{A. Politeness as an Integral Part in Human Interaction}

Leech (1983, p.1) was depicted communication as problem-solving task. Using language appropriately means that the speaker wants to build up the best frame in the hearer's consciousness. In this direction, the hearer makes some efforts to understand the real want of the speaker. Therefore, the hearer and speaker should interact correctly in order to build an understandable bridge between them.

\section{B. Grice's Cooperative Principle}

In order to build and make a meaningful communication, the hearer and the speaker should cooperate with each other. It should be noted that this cooperation is merely mutually exclusive and both of the parties should assume themselves in the circle of interaction. Grice (1975) stated that "our talk exchanges do not normally consist of a succession of disconnected remarks, and would not be rational if they did. They are characteristically, to some degree at least, cooperative efforts; and each participant recognizes in them, to some extent, a common purpose or a set of purpose, or at least a mutually accepted direction. We might then formulate a rough general principle which participants will be expected (ceteris paribus) to observe, viz: ' Make your contribution such as required, at the stage at which it occurs, by the accepted purpose or direction of the talk exchange in which you are engaged. One might label this the Cooperative Principle."

Grice categorizes the Cooperative Principle into four categories which they very necessary for achieving an efficient communication between the parties. They are as follows:

\section{(I) Quantity Maxim}

(1) Make your contribution as informative as required (for the current purpose of the exchange).

(2) Do not make your contribution more informative than is required.

\section{(II) Quality Maxim}

Try to make your contribution one that is true. (1) Do not say what you belief to be false. (2) Do not say that for which you lack evidence.

(III) Relation Maxim

Be relevant

(IV) Manner Maxim

Be perspicuous. (1) Avoid obscurity of expression. (2) Avoid ambiguity. (3) Be brief (avoid unnecessary prolixity). (4) Be orderly

It is completely natural to say that real languages do not always comply with Cooperative Principle. In this direction, one might say that politeness principle comes from the violation of the above-mentioned process of Cooperative Principle. Therefore, it should be considered that these four categories are not the absolute license of every culture. All cultures can be able to add some maxims they want and then they can break them. Grice's theory has been criticized from various angles. For instance, Thomas (1994, p.760) addressed that "Grice own definition of the Cooperative Principle is ambiguous and inconsistent." Then he said that different interpretations come from the Grice's maxims and "the very term Cooperation is misleading, since what in everyday term would be seen as highly uncooperative behavior, such as arguing, lying, hurling abuse, may yet be perfectly cooperative according to some interpretations of Grice's (1975) term." In spite of the intensive critics, Grice's maxims prepare the situation for the diverse studies such as politeness theories.

\section{The Important Theories of Politeness}

Lots of studies would be done about politeness in translation and cross-cultural studies. After Brown and Levinson's (1978) "Universal in language usage: Politeness Phenomena" politeness became the best topic to negotiate amongst translators and linguist. Amongst the linguist, Robin T. Lakoff was the first person who scrutinized politeness in the scope pragmatics. Lakoff defined politeness as (in Eelen, 2001, p.2) "a system of interpersonal relations designed to facilitate interaction by minimizing the potential for conflict and confrontation inherent in all human exchange." Lakoff (1990) addressed "politeness rule" as: 
"[....] If one seeks to communicate a message directly, if one's principal aim in speaking is communication, one will attempt to be clear, so that there is no mistaking one's intention. If the speaker's principal aim is to navigate somehow or other among the respective statuses of the participants in the discourse indicating where each stands in the speaker's estimate, his aim will be less the achievement of clarity than an expression of politeness, as its opposite."

Another politeness theorist will be Geoffrey Leech (1983) which labeled politeness strategy as part of interpersonal rhetoric. He proposed that in order that politeness would be occurred, communication should break the Grice's conversational maxims. He then proposed Politeness Principle (PP). Leech (1983) said that the Politeness Principle is based on the premise that interlocutor seeks to minimize the expression of impolite beliefs and maximize the expression of polite beliefs. Leech (1983, p.132) proposes the categories of his Politeness Principle (PP) which are as follow:

(I) Tact Maxim

(a) Minimize cost to other

(b) Maximize benefit to other

(II) Generosity Maxim

(a) Minimize benefit to self

(b) Maximize cost to self

(III) Approbation Maxim

(a) Minimize dispraise of others

(b) Maximize praise of others

(IV) Modesty Maxim

(a) Minimize praise of self

(b) Maximize dispraise of self

\section{(V) Agreement Maxim}

(a) Minimize disagreement between self and other

(b) Maximize agreement between self and other

(VI) Sympathy Maxim

(a) Minimize antipathy between self and other

(b) Maximize sympathy between self and other

In all of these categories, Leech stated that the Politeness Principle cannot be applied for all the cultures and do not cover all aspects of pragmatics. Therefore, it should be noted that the translator must be familiar with socio-pragmatics in order to analyze different cultures and societies. In this regard, Politeness Principle of Leech has been criticized by Watts et al (1992, p.7) in that "far too theoretical to apply to actual language usage and too abstract to account for either the commonsense notion of politeness or some notion which fits into a general theory of social interaction."

The last politeness theory is pertained to Penelope Brown and Stephan C. Levinson. Brown and Levinson (1987, p.59) made an influential situation in politeness theory. It should be mentioned that their theory is based on "face" concept which later defined as public self-image in this direction. Face concept involves into two wide concepts: (1) positive face and (2) negative face. The former deals with solidarity and membership of the speaker and hearer in the circle of interaction, while the latter relates to deference strategy and it frees own self from imposition. This theory expounds that most of the speech acts threaten either the hearer's or speaker's face want. In this regard, one must utilize politeness to minimize the possibility of face threatening act (FAT). To cut the long story short, it can be stated that face threatening act can be categorize either off or on record. Off records allude to utterances which are not directly addressed to another. While on records refer to utterances which are directly addressed to another completely. In these two cases, politeness strategy will be of high importance and the translator should be aware of transferring the correct sense of theses stages to saturate the needs of the target reader thoroughly. Brown and Levinson proposed possible politeness strategies which are as follow: 


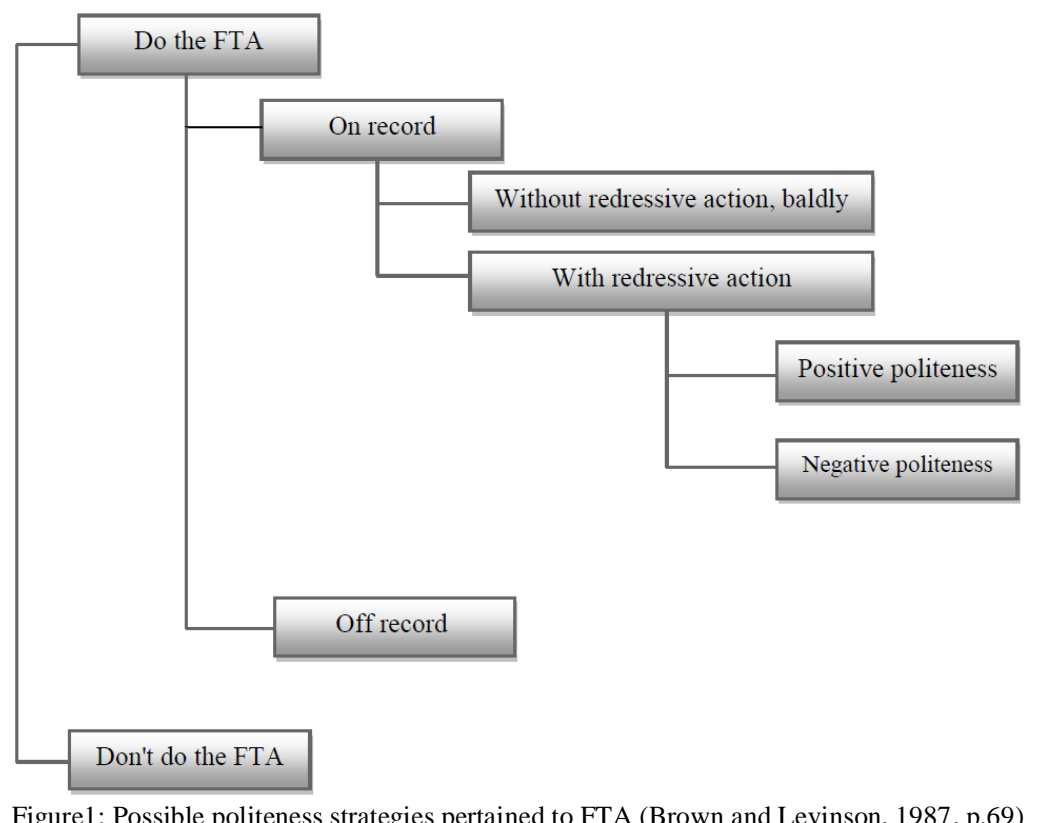

Among these categories, "off record" may have different interpretation amongst cultures. In this case, the translator cannot resort him or herself to literal or one to one correspondence of the target language. But, the most important fact is that off record strategy can soften the indirectness and then remove threat. And finally, it is well worth saying that the translator should consider all aspects of politeness strategies in order to deal with these kinds of situations to remove any menace for target reader and he or she can transfer the near sense of the source language.

\section{Politeness Translation Strategies}

In this section, this paper seeks to investigate some strategies in politeness. These kinds of strategies are contextbased and the translator should pay attention to the situation of the strategies being utilized in this direction. This paper scrutinizes two kinds of politeness strategies in translation: (1) solidarity (positive) strategies and (2) deference (negative) strategies

\section{A. Solidarity Strategies}

\section{(A). Reader Attention}

In the circle of communication and interaction, two parties are the most important factor which is well worth attending. In this direction, reader is context-based and needs to be well paid attention. Saturating the needs of the reader is an ordeal task for the translator or interpreter. Some factor should be considered when dealing with the target language in general such as cultural clashes, connotative meaning, and pragmatic circle. In these afore-mentioned cases, language sensitivity is of great importance. For instance, "Vai ancora a scuola?" in the Italian language expressed in a friendly way. The reader in this language knew the tone of the sentence but the problem is that how the renderer can be able to transfer the tone of the sentence in the target language and attract the attention of the reader. How can the reader be able to perceive the sense of the text? English language is genderless and cannot be able to ruminate the exact speaker of the text. Therefore it is better to prepare the context for the reader to connect him or herself to the content of the text and let him or her judge about the interpretation of the text. In politeness translation, the translator should pay attention to the speaker of the text. For example, in the Italian language the speaker enunciates the polite words via some vestiges such as "il Caro" and "la Cara". The former is utilized for the masculine gender and the latter is used for the feminine gender. But the problem is that in the English language, the translator cannot clarify the exact gender of the text and should prepare the context for the reader of the text.

\section{(B). Magnifying}

This technique is utilized when the translator wants to show the intensification of the text for the reader. This technique follows the intensifying adverbs such as absolutely, very, too, and really. Whenever these adverbs follow the polite word, they cause the translation more direct and more intensive for the target reader. For instance, "Veramente, $t i$ voglio molto bend" in the Italian language contains to important factors such as "veramente" and "ti". The former expresses the intensive adverb and the latter is gender based pronoun. The interpreter or the translator should be aware of the tone of the sentence and render "I'm pretty fond of you". This translation prepares the romantic situation for the reader and reader knows this sentence will be expressed by either a friend or the lover. Magnifying the polite word in translation is of great importance to connect the reader to the source language text. As another example, "Apprezziamo molto il suo aiuto la scorsa settimana" in the Italian language contains some element to be noted. First, the adverb "molto" acts as the intensifying adverb and then the word "suo" acts as a possessive pronoun in this sentence. This 
sentence revealed that the speaker wants to prepare the formal situation by using such words. Therefore, the formal rendering of this sentence will be "we really appreciate your help last week". Consequently, the reader understands that the possessive pronoun utilizes in the formal way and the addressee will be in high rank.

\section{(C). Eschewing dispreferred structure}

The well-trained translator should decrease the offensive degree of some expression. In this sense, the inflexible group will be feminine gender who shuns expressing something really clarifying. Therefore, the translator should amalgamate every ilk of people in this track. In this case, the renderer can be able to utilize two techniques (1) using euphemism and (2) seeking common ground which the speaker agrees on. The latter case will not be used for politeness strategies in translation but the latter case will be utilized brilliantly and then lessens the degree of disagreement. For instance,

A- Bene, ti piace il mio vesitio?

B- Esso ti addata adequatamente (il vestito più brutto che abbia mai visuto)

In this case, the translator should consider the audience or the reader of the text and then he or she has better to use the common ground which the reader will agree on. The English translation of the afore-mentioned sentence will be:

A- Well, you like my new dress?

B- It fits you suitably (the ugliest dress she has ever seen)

In the English rendering, the translator resorts him or herself to technique of "modulation" (Vinay and Darbelnet, 1958/1995, p.58). The translator changes the direction of the sentence and then lessens the degree of Impoliteness despite his or her will.

\section{(D). Be Propitious}

This is one technique of politeness in translation which is aimed at minimizing the face threatening act. In this interaction, the speaker, renderer, and the hearer are in the circle of cooperation. The renderer should be aware of the positive outcome of transfer. This technique is the most drastic ones in conveying the main essence of politeness in translation. Optimism is of great importance in simultaneous interpreting. Therefore, in this case, the translator or the interpreter should get fully familiar with the target language. "Be Propitious" is context-based for which the interpreter should regard all aspects of the target culture in order to convey the main content of the source language. For instance, "Non, ti dispiace se scrivo qui?" This sentence contains the word "dispiace" which is completely polite in the source language. "Dispiace" is a speech event which considers the permission-based approach (Archer, Aijmer, Wichmann, 2012, p.43). Therefore, the renderer should translate such sentence as "Do you mind if I write here?" the English rendering diminishes face threatening act (FTA) in order to lessen the degree of imposition in the target language.

\section{(E). Reciprocal Assumption}

This technique is used for highlighting the beneficial relationship. It can be stated that reciprocal assumption is mutually exclusive. Some languages such as the Italian, Persian, Japanese, and Korean languages use compliments as an integral part in speaking. Most of the renderers observe this technique in their translation to show the color of the source language. But the problem is that the other languages such as the English, Russian, and Spanish don't have such compliments in their culture. Therefore, how can the renderer transfer such issues in the target language to saturate the needs of the target reader? In these cases, the translator should make politeness as gloss translation. Or he or she can utilize the technique of "Dash-Array (Darrey)" (Akbari, 2011) to show the generic and specific aspects of gloss translation completely. For example, "Questo è il tuo turno" can be translated as "This is your shot". These sentences show that the translators adhere themselves to preparatory condition (Archer, Aijmer, Wichmann, 2012, p.38) which expresses that the source language benefits the target language. Therefore, it should be stated that politeness theory is coincided to speech event of the target language.

\section{B. Deference Strategies}

\section{(A). Indirect Rendering}

This case (Indirect Rendering) is used for formal and official situation. Most of the renderers utilize this technique when dealing with legal text. Legal text should be translated carefully with observing the ranks and statuses. Both the Italian and English languages observe such technique in their translations to remove any offense or obscurity in both source and target languages. In most of the conversations, the speakers use mitigating devices such as "Please", "Could you", and "Would you". Dealing with these deference politeness strategies, the renderer should translate the source words in accordance with the target language to diminish any incoming impositions. Natural equivalence or one to one correspondence is of great importance in this group. Everything can be said is coincided to the target language and vice versa $(\mathrm{A} \rightarrow \mathrm{B}$ and $\mathrm{B} \rightarrow \mathrm{A})$. For example, "Mi può fare un favore per piacere?" can be rendered naturally as "Can you do me favor please?" These two sentences observe the deference politeness strategy and they minimize the effect of face threatening act (FTA) completely. And finally, should the translators encounter direct rendering, they must resort themselves to directional equivalence which is completely culture-based and should be done cautiously to lessen the degree of reader's imposition in the target language.

\section{(B). Diminishing Imposition}

In translation tasks, the translator can be able to create a rapport amongst the source language, the translation, and the target language. But the important note is that how it is possible to do so. The renderer acts as the mediator between the two poles. Therefore, he or she should lessen the degree of imposition in the target text. Translation is a kind of 
business which it tries to connect every group in this circle. In some situations, the renderer or especially the interpreter must modify the degree of politeness in order to meet the needs of the reader. This case is completely context-based. To put it in the nutshell, the translator/interpreter may determine the red line in his or her translation to keep every ilk of people in this regard. Face Threatening Act plays the main role in this case. So, the translator should replace the intended imposition to the less imposition in the target language. As a result, the less the imposition will be, the less the risk of Face Threatening Act. For example, "Voule dedicare un po' di tempo per me?" can be rendered as "Would you devote a little bit time to me?". In the Italian example, the source language utilizes the word "un po"' to lessen the degree of imposition in the target language. It should be noted that diminishing imposition s well coincided to indirect speech utilized in formal situation in order to observe the status of the reader or hearer of the text.

\section{(C). Be ambiguous}

A good rendering is the one which prepare the situation for the reader to judge about the text. A good rendering is the one which put the reader in an uncertain situation. Uncertainty in translation is an asset for the translator to create the unequilibrium scale. But one cautious note should be taken. In which kind of text can the translator create the unequilibrium scale in the target language? For example, in technological or medical text, the translator doesn't allow to pass the red line. Because the afore-mentioned texts are pertained to way of life of people and should not be put in danger by different interpretations. In poetic text, the reader and the renderer can pass the red line and make different interpretations. Because this kind of text is related to feeling of people and the people want to infer what they want. And how will it be relate to politeness in translation? Politeness is the sense of ambiguity in the target text which shows the double-sidedness of the target language. For instance, compliments in eastern countries are norms of life while they have the pejorative meaning in the western countries. In this kind of situation, the translator puts him or herself in a dilemma that he doesn't really know what to do to saturate the needs of the target reader and besides he or she wants to show the system of source language norm. Therefore, the renderer must translate ambiguously to connect these poles. It should be noted that the translator cannot change the meaning of the source text completely. For example, "Funziona davverro?" is a kind of ambiguous sentence which let the reader of the text judge about it whatever he or she wants. One of the meanings of the sentence is pertained to literal or natural meaning of the sentence. While other alludes to dysfunctionality of the sentence and it puts the speaker in dilemma. Therefore, literal meaning of the sentence is in accordance with direct meaning and the ambiguous meaning is pertained to indirect meaning of the sentence. As a result, the polite word should be rendered by the norms of the target culture to create a rapport between the poles in translation.

\section{(D). Rapprochement}

The last technique of politeness translation is to build up the rapport connection between the source and the target languages. Utilizing rapprochement in the target text is extremely tied with the type audience of the target language. In these situations, first, the renderer should pay attention to the status or social position of the intended audience. Therefore, the translator should apply mitigating device to remove any offence or disrespection in the target language. Second, the translator should inspect language patterning in this direction. For instance, in the Russian language, the speaker does not use any mitigating devices in his or speaking while in the English language; the speakers always utilize the mitigating device to respect the hearer or reader of the text. Language patterning comes from language sensitivity. It means that, the intended language eschew utilizing the eccentric forms and always it wants to nativize the words and figures them in accordance with the target language (Akbari, 2013, p.24). Therefore, language patterning and decoding ability in translation of politeness are of great importance. For example, from the long time ago; the English families would be famous for nobility and dignity. In all of the situations, they observed how to use the polite word in their daily conversation to progress their works. So, one might conclude that language patterning of the intended language will be of high respection.

Last but not least, all of these procedures are well-tested in diverse situations. But the most important fact is that, the translator should render indirectly to respect or defer to every ilk of people. It can be stated that, sometimes these procedures overlap with each other and make rendering difficult to perceive. In these positions, the renderer should put his or her effort to connect the two poles in translation via the technique of loss and gain. Loss and gain technique is used in pivotal situation in that it removes some parts of translation and then it utilizes (compensate) in other parts of the translation. It means that the translator wants to keep the source and target languages altogether. Therefore, loss and gain causes the politeness to transfer to the target text completely and saturates the taste of the reader.

\section{DISCUSSION}

Every rendition is the symbol of the source language. Therefore, the translator should put his or her effort to show his or her culture brilliantly. Translation of politeness across cultures is an ordeal work. The translator should consider every sort of people, taste, traits, and backgrounds. Every person has his or her own taste of understanding the text. Therefore, the renderer should be cautious in translation of the text. In all these cases, the translator should be welladapted to transfer and convey the main essence of the source language politeness. Nord defines translation (1997, p.18), "translation as a form of mediated cross cultural communication." It means that, everything can be said in one language, it too can be said in another language as well, but the form is different. Therefore, Nord drew the figure to show the process of transference into the target language: 




In this figure, the translator is a mediated agent to connect the poles of the source to that of the target one. In this direction, the translator can also use translational and non-translational text to convey the essence $\mathrm{f}$ the text. In politeness translation, the renderer can utilize both same and new function. The former will be used for natural equivalence. Natural equivalence in politeness translation will be used one to one correspondence i.e. solidarity politeness in the source language is in accordance with the target one. The latter alludes to deference strategy (directional equivalence) in negative politeness. It means that the translator should create the same situation in the target language. For instance, the way of expressing compliment in the source will be different from the target language. One important note should be taken that during the rendition, the renderer should ordain the red line in order not to pass this line and he or she causes to modify the deep structure of the ext. the translator can embellish the surface structure of the text by adding or omitting some particular discourse markers. In "New Function" part of the figure, the translator wants to make cultural diversification while in "Same Function" part; the translator is going to procure cultural homogeneity. And finally, "Non-translational" part of this figure refers to particular situation in which the source language is completely different from the target language. In this direction, the translator utilizes the technique of gloss and drafting translation as a footnote. But it will be recommended that the translator create the similar situation in these special cases to saturate the taste of the reader.

Last but not least, it is important to say that this study has been based on the English-Italian instances and does not show any corresponding examples related to the Persian language. It is hoped that some studies would address the case with other languages and would accordingly set out to test the workability of the politeness translation procedures on the large number of texts in the near future.

\section{CONCLUSION}

This study sought to investigate the politeness translation strategies in the source and target language. Translation of politeness in cross-cultural communication would be of great importance in Translation Studies. Therefore, this paper prepared some procedures to convey the near sense of translation of politeness in the target language. Language patterning and the role of decoding ability would be more drastic in translation. Politeness translation needs considerable attention in every field of study. The translator should also work on people's interaction in different situation in order to make a frame of his or her study. Politeness paradigm is also utilizable in natural and directional equivalence. In the light of these expounds, one can conclude that every language which has the same ancestor as the other languages, it applies for natural equivalence in politeness translation. While others have diverse ancestors, they apply for directional equivalence and they have to create the similar situation in the target language to convey the near sense of the polite words. And finally, saturating or meeting the needs of the reader is of great importance and the translator should create the position in translation which the audience can be able to touch the workability of the rendition.

\section{REFERENCES}

[1] Akbari, Alireza. (2011). Intermediacy Model of Translation in Gray Zone, London, Oxford University Press, Unpublished Book.

[2] Akbari, Alireza. (2013). Exploring into the New Model Procedure in Translation: Wafting as a Case in Point, International Journal of Education and Literary Studies, Vol 1, 19-20. Doi: 10.7575/aiac.ijels.v.1n.2p.18, http://dx.doi.org/10.7575/aiac.ijels.v.1n.2p.18.

[3] Archer, D., Aijmer, K., and Wichmann, A. (2012). Pragmatics: An Advanced resource Book for Students, London and New York: Routledge.

[4] Brown, Penelope and Steven C. Levinson (1987). "Universals in Language Usage: Politeness Phenomena." In E. Goody (ed.), Questions and Politeness. Strategies in Social Interaction. Cambridge: Cambridge University Press. 
[5] Chamberlain, L. (1998/2000). "Gender and Metaphorics of Translation", Signs 13: 457-72, Reprinted in L. Venuti (ed.) (2000), 315.

[6] Eelen, Gino. (2001). A Critique of Politeness Theories, Manchester: St. Jerome Publication.

[7] Grice, H. Paul. (1957). "Logic and Conversation." In P. Cole and J. Morgan (eds.), Syntax and Semantics, Vol. 3: Speech Acts. New York: Academic Press.

[8] Hatim, B. and I. Mason. (1997). The Translator as Communicator, London and New York: Routledge.

[9] Lakoff, R. (1990). Talking Power, New York, Basic Books.

[10] Leech, Geoffrey. (1983). Principles of Pragmatics, London: Longman.

[11] Nida, E. A. (1964). Towards a Science of Translating, Amsterdam, Leiden: E. J. Brill, 156-171.

[12] Nord, C. (1997). Translating as Purposeful Activity. Functionalist Approaches Explained, Manchester: St. Jerome Publication.

[13] Oxenden, Clive and Latham-Koenig, Christina. (2008). American English File 3, New York, Oxford University Press.

[14] Thomas, J. (1994). "Cooperative Principle." In R.E. Asher and J.M.Y. Simpson (eds.), An Encyclopedia of Language and Linguistics, Oxford: Pergamon Press.

[15] Vinay, J. and Darbelnet, J.C. (1965). Stylistique Comparèe du Français et de l'anglais. Paris: Didier.

[16] Watt, Richard J. (1992). "Linguistic Politeness and Politic Verbal Behavior: Reconsidering Claims for Universality." In R. Watt, S. Ide, K. Ehlich (eds.), Politeness in Language: Studies in its History, Theory and Practice, Berlin: Mouton de Gruyter, 7.

[17] Yule, George. (1974). Pragmatics, New York, Oxford University Press.

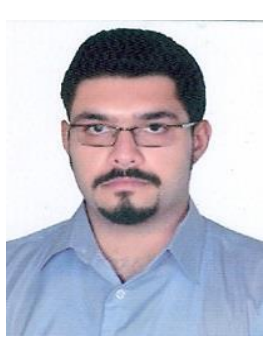

Alireza Akbari is an MA candidate of Translation Studies in University of Isfahan. He is the founder of Intermediacy Theory of Translation in Gray Zone. He is familiar with the Italian and German languages. He also wrote some articles on translation and applied linguistics. His main interests are Theories of Translation, Philosophy of Translation, and Equivalence Paradigm in Translation, Bi-directional, and Liaison Interpretation. 